\title{
ÁGUA EXÓGENA EM SUCO DE UVA OBTIDO PELO MÉTODO DE ARRASTE A VAPOR
}

\section{EXOGENOUS WATER IN GRAPE JUICE OBTAINED THROUGH THE STEAM EXTRACTION METHOD}

\author{
Bruna Bresolin ${ }^{1}$; Márcia Arocha Gularte ${ }^{2}$; Vitor Manfroi ${ }^{3}$ \\ ${ }^{1,2}$ Universidade Federal de Pelotas- UFPel - Pelotas - Brasil brunabre@ gmail.com \\ ${ }^{3}$ Universidade Federal do Rio Grande do Sul - UFRGS - Porto Alegre - Brasil manfroi@ufrgs.br
}

\begin{abstract}
Resumo
O consumo de suco tem aumentado nos últimos anos devido ao aumento da procura, por parte dos consumidores, por alimentos saudáveis, e o suco de uva é rico em substâncias antioxidantes, benéficas a saúde. A comercialização de suco de uva de janeiro a março deste ano já foi 22,31\% superior ao comercializado em 2010. O método de extração do suco de uva por arraste a vapor é muito utilizado por pequenos produtores na Serra Gaúcha, RS que industrializam sua produção, agregando valor à matéria-prima e aumentando sua renda. O equipamento necessário apresenta baixo custo e é de fácil manuseio. No entanto, devido ao contato entre a matéria-prima e o vapor, o método proporciona a incorporação de água exógena ao suco, o que descaracteriza a denominação de suco integral de uva, além de proporcionar diluição no conteúdo de sólidos solúveis. Assim, o objetivo deste trabalho foi avaliar a incorporação de água exógena na obtenção de suco de uva utilizando o método de arraste a vapor, através da determinação da razão isotópica 180/160 da água incorporada ao suco de uva durante o processamento, em intervalos de 15 minutos, durante três horas. Verificou-se que a maior incorporação de água ocorreu nos primeiros 30 minutos de extração e a partir dos 150 minutos.
\end{abstract}

Palavras-chave: suco de uva; água exógena; panela extratora.

\section{Introdução}

O suco de uva teve sua origem no ano de 1868, nos Estados Unidos, onde um grupo de religiosos obteve um vinho não fermentado, utilizando as ideias de Pasteur. Muito antes disso, gregos e romanos já utilizavam o calor para concentrar mosto de uva e permitir sua conservação (CAINELLI, 2006; MARZAROTTO, 2010).

Anualmente são produzidas 1,2 milhão de toneladas de uva, cerca de $45 \%$ é destinado a elaboração de vinhos, sucos e derivados e 55\% são comercializados in natura. Do total de produtos industrializados, $77 \%$ são vinhos e $9 \%$ são sucos. Grande parte da produção é destinada ao mercado interno, sendo o principal produto de exportação, em volume, o suco de uva, com $15 \%$ do total 
destinado a exportação (IBRAVIN, 2010). Segundo dados da União Brasileira de Vitivinicultura (2011) de Janeiro a Março deste ano já foram comercializados 17.612 .744 litros de suco de uva, uma variação de 22,31\% em relação a 2010 e foram exportados 406.127 litros, uma variação de $215,25 \%$ em relação ao volume comercializado no ano passado.

O suco de uva é definido como uma bebida não fermentada, não diluída, obtida do mosto simples, sulfitado ou concentrado, de uva sã, fresca e madura, obtida da parte comestível da uva (Vitis ssp.), através de processo tecnológico adequado (BRASIL, 1988; 1990; 2000). A Tabela 1 indica os limites analíticos estabelecidos pela legislação para o suco de uva.

Tabela 1 - Limites analíticos estabelecidos pela legislação para o suco de uva

\begin{tabular}{ccc}
\hline Avaliações & Mínimo & Máximo \\
\hline Sólidos solúveis em ${ }^{\circ}$ Brix, $20{ }^{\circ} \mathrm{C}$ & 14,00 & - \\
Acidez total expressa em ácido tartárico $(\mathrm{g} / 100 \mathrm{~g})$ & 0,41 & - \\
Açúcares totais naturais da uva $(\mathrm{g} / 100 \mathrm{~g})$ & - & 20,00 \\
Sólidos insolúveis $\%$ v/v & - & 5,00 \\
Acidez volátil em ácido acético & - & 0,050 \\
\hline Fonte: Ministério da Agricultura, Pecuária e Abastecimento- Instrução Normativa ${ }^{\circ}{ }^{\circ} 01$, de 07 de janeiro de 2000.
\end{tabular}

A composição química do suco de uva depende da matéria-prima utilizada, cultivar, maturação, tratamentos a que a uva foi submetida e ainda das condições climáticas. A composição do suco de uva, se não concentrado e desnaturalizado, é semelhante à uva de origem, exceto nos teores de fibra e óleo, pois estes compostos são encontrados em maior quantidade nas sementes. A tecnologia de processamento também influencia a composição dos sucos, pois proporcionam diferentes níveis de extração de algumas substâncias. O tempo e a temperatura são os principais fatores a serem considerados (MARZAROTTO, 2010).

O principal constituinte do suco de uva, em quantidade, é a água, seguido de açúcares, polissacarídeos, pectinas, ácidos orgânicos, polifenóis, compostos nitrogenados, sais minerais, vitaminas, polipeptídeos e proteínas (MARZAROTTO, 2010). De acordo com Vogt (1972) os principais açúcares são a glicose e a frutose e os principais ácidos são o tartárico e o málico. Devido a sua composição o suco de uva é considerado uma bebida energética e nutritiva (MARZAROTTO, 2010). Dani et al. (2011) afirmam que os sucos de uva, brancos ou tintos, são ricos em compostos bioativos, que auxiliam na prevenção de doenças como o câncer e doenças cardíacas. O suco é rico em polifenóis como os ácidos fenólicos, antocianinas e taninos, que possuem atividade antioxidante e regulam a permeabilidade e resistência do sistema vascular (RIZZON e MENEGUZZO, 2007; MARZAROTTO, 2010).

As variedades de uva destinadas a produção de suco devem ter bom rendimento em mosto, adequada relação doçura/acidez, bom nível de maturação e sanidade, além de possuir um sabor que agrade ao consumidor. O grupo das americanas, Vitis labrusca, Vitis aestivalis e Vitis bourquina, 
entre estas as variedades Isabel, Bordô, Concord e Jacquez são as mais utilizadas (RIZZON et al., 1997; MARZAROTTO, 2010). A variedade Concord apresenta boas características de sabor e aroma, sendo referência de qualidade, a Isabel é bastante utilizada devido ao volume de produção disponível e a Bordô, Jacquez e Seibel participam em menor quantidade (CAMARGO, 2005). De acordo com Camargo (2005) a referência de qualidade organoléptica do suco de uva está nas características de sabor e aroma das uvas labruscas. O suco da cultivar Bordô, apesar de apresentar baixo rendimento, é utilizado para melhorar sucos de outras variedades, como Isabel e Concord, devido a sua elevada intensidade de cor e aroma (RIZZON et al., 1997; MARZAROTTO, 2010).

A extração de suco de uva pelo método de arraste a vapor representa uma alternativa ao pequeno agricultor, para viabilizar economicamente a pequena propriedade rural, assim como as demais atividades de agroindustrialização. A transformação da matéria-prima própria evita a transferência de renda do setor rural para o industrial, proporcionando a agregação de valor, aproveitamento dos excessos de produção, movimentação monetária constante durante o ano, inclusão e valorização do trabalho feminino e dos jovens no processo produtivo (IPÊ, 1997; RIZZON et al., 1997). O método de extração por arraste a vapor se popularizou entre os pequenos produtores de uva que começaram a transformar sua produção, com o objetivo de agregar valor a matéria-prima e aumentar a renda da família.

O método de arraste a vapor é uma derivação do Método Welch, considerado o primeiro processo de extração através do calor. O Método Welch foi desenvolvido em 1869, quando um dentista, Dr. Thomas Welch, cozinhou uvas da cultivar Concord e utilizou sacos de pano para extrair o suco, após engarrafou e utilizou a pasteurização para a conservação (MARZAROTTO, 2010).

O conjunto extrator é formado por um depósito de água, que é aquecido para geração do vapor, sobre ele é colocado um recipiente com abertura cônica no centro para passagem do vapor e uma abertura lateral para escoamento do suco e acima é sobreposto um recipiente perfurado onde as uvas são colocadas. Para obtenção do suco pode-se utilizar apenas uma panela, ou é possível dispor um maior número de panelas em série, otimizando o tempo de processamento. O rendimento neste processo fica entre 50 e $60 \%$ (RIZZON et al., 1997).

A Instrução Normativa n ${ }^{\circ} 01$, de 07 de Janeiro de 2000, do Ministério da Agricultura, Pecuária e Abastecimento (MAPA) define o suco de uva como uma bebida não fermentada, não diluída, obtida da parte comestível da uva (Vitis ssp.) através de processo tecnológico adequado, ou seja, no suco de uva não é permitido a adição de água. O Decreto n ${ }^{\circ} 99066$, de 08 de Março de 1990, define suco de uva integral ou simples aquele que não teve adição de açúcar e que se encontra na sua concentração natural. Como no processo por arraste a vapor ocorre o contato da uva com o vapor e consequente incorporação de água, o produto originado não poderia ser comercializado com 
a denominação de "suco integral de uva" e sim com o nome de néctar ou refresco. O Decreto n. ${ }^{\circ} 6871$, de 04 de Junho de 2009, define néctar como uma bebida não fermentada, obtida da diluição, em água potável, da parte comestível do vegetal ou de seu extrato, adicionado de açúcares, destinado ao consumo direto e refresco, ou bebida de fruta ou de vegetal, como bebida não fermentada, obtida pela diluição, em água potável, do suco de fruta, polpa ou extrato vegetal de sua origem, com ou sem adição de açúcares. A legislação brasileira não define uma percentagem de água exógena que pode ser incorporada ao suco de uva. Ao mesmo tempo, não há um método oficial para determinação da água exógena em suco de uva, o método utilizado é o descrito pela Instrução Normativa n. ${ }^{\circ}$ 10/2009 do MAPA (BRASIL,2009), que oficializa a metodologia analítica para determinação da razão isotópica $180 / 160$ da água dos vinhos. Para a determinaçao da percentagem de água exógena em suco seria necessária a determinação de parâmetros específicos para esse produto.

O uso do método de extração por arraste a vapor está muito difundido nas propriedades rurais do Estado do Rio Grande do Sul, tanto para produção de suco para consumo próprio, como para comercialização. A Superintendência do Ministério da Agricultura, Pecuária e Abastecimento no Estado fornecia o registro do produto até o ano de 2010, quando questionou-se a incorporação de água ao suco e houve a suspensão provisória de novos registros, bem como a proprrogação de antigos. Porém, houve uma nova orientação do MAPA e atualmente, a concessão e prorrogação de registros será concedida por mais três anos. Neste período grupos de trabalho deverão estudar o assunto e provavelmente irão propor a criação de um regulamento técnico específico para este produto, alterações nos equipamentos e na legislação existente.

No processo industrial é utilizado o método enzimático, no qual a uva, após o esmagamento, é aquecida a no mínimo $65{ }^{\circ} \mathrm{C}$ em um termo macerador tubular, para extração de compostos fenólicos responsáveis pela cor. Em seguida, o mosto é adicionado de enzimas pectolíticas comerciais, permanecendo nos tanques de tratamento enzimático por uma a duas horas, em temperatura entre 55 e $60{ }^{\circ} \mathrm{C}$. Depois da extração do suco, este segue para as etapas de clarificação, pasteurização e engarrafamento (MARZAROTTO, 2009; RIZZON e MENEGUZZO, 2007). Outro método comumente utilizado é o Método Flanzy, que possui baixo custo e é de fácil execução. Este método prevê o desengace e esmagamento da uva seguido do abafamento com dióxido de enxofre, que promove a extração da cor da casca e garante a estabilidade microbiológica e enzimática do suco. O suco pode ser armazenado em tanques e a medida que vai sendo engarrafado é dessulfitado (MARZAROTTO, 2009).

A incorporação de água no suco não constitui em problemas de saúde para o consumidor, mas se a água adicionada ao suco não é declarada, através da denominação da bebida, o consumidor pode estar comprando um produto que não corresponde as suas expectativas. Desse modo as 
indústrias podem adicionar água para aumentar o rendimento do suco e desta foma podem estar enganando o consumidor.

O objetivo deste trabalho foi avaliar a incorporação de água exógena na obtenção de suco de uva utilizando o método de arraste a vapor. Este método é utilizado por grande parte dos pequenos agricultores familiares que transformam a matéria-prima própria em suco, pois o método é de fácil operação e não apresenta custos altos de instalação e operação.

\section{Material e Métodos}

As amostras de suco da cultivar Bordô (Vitis labrusca) foram obtidos pelo processamento das uvas pelo método de arraste a vapor. As uvas utilizadas foram higienizadas, desengaçadas e após foram transferidas para o conjunto extrator.

Figura1- Fluxograma do processamento de suco de uva pelo método de arraste a vapor

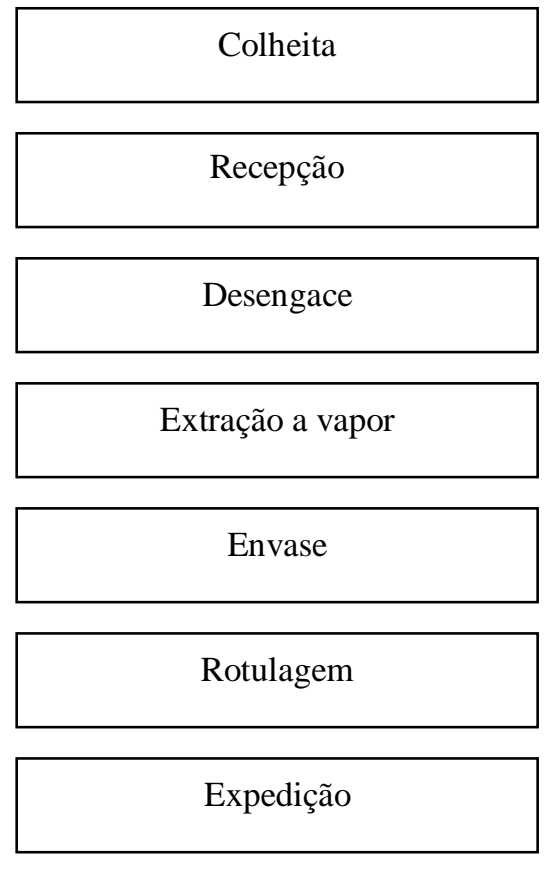

Fonte: Autor

As amostras de suco de uva foram retiradas a cada 15 minutos, a partir do momento em que o suco começou a escorrer pela abertura de captação da panela extratora, totalizando 12 períodos. Os tempos analisados foram 15, 30, 45, 60, 75, 90, 105, 120, 135, 150, 165 e 180 minutos. Foram realizadas duas extrações para cada tratamento, considerando cada extração como uma repetição. $\mathrm{O}$ suco foi envasado a quente em garrafas de vidro com capacidade de $250 \mathrm{ml}$ e identificados. A temperatura de extração não foi monitorada. No processo de extração por arraste a vapor o suco é, na grande maioria das vezes, envasado em garrafas de vidro que são resistentes a temperatura de extração, possibilitando a pasteurização. 
Foram realizadas análises de $\mathrm{pH}$ em aparelho pHmetro Quimis, modelo Q- 400A, calibrado com soluções tampão de pH 4,0 e 7,0, conforme AOAC (1995). Os sólidos solúveis foram determinados em refratômetro marca Carl Zeiss, compensando-se a leitura para $20^{\circ} \mathrm{C}$, conforme Brasil (2005). As análises foram realizadas para cada tratamento.

A análise da razão isotópica 180/160 foi realizada no Laboratório de Referência Enológica do Estado do Rio Grande do Sul (LAREN), Caxias do Sul, RS. A determinação foi realizada por espectroscopia de massa de razão isotópica (EMRI ou "IRMS”) de padrão internacional (VSMOW) a partir das correntes iônicas geradas no íon $\mathrm{CO}_{2}+$, com as espécies moleculares isotópicas $\mathrm{m} / \mathrm{z}=44(12 \mathrm{C} 16 \mathrm{O} 16 \mathrm{O})+, \mathrm{m} / \mathrm{z}=45(13 \mathrm{C} 16 \mathrm{C} 16 \mathrm{C})+\mathrm{e} \mathrm{m} / \mathrm{z}=46(12 \mathrm{C} 16 \mathrm{O} 18 \mathrm{O})$ de acordo com a Instrução Normativa $\mathrm{n}^{\circ} 10$ de 14 de abril de 2009, do Ministério da Agricultura, Pecuária e Abastecimento (BRASIL, 2009).

Os isótopos são átomos que apresentam o mesmo número atômico, mas apresentam números de massa diferentes, pertencendo ao mesmo elemento químico (USBERCO e SALVADOR, 1999). Alguns isótopos são naturalmente encontrados na natureza, como isótopos de hidrogênio, oxigênio, carbono, nitrogênio, enxofre e possuem importância na datação de artefatos de interesse histórico e adulterações em alimentos (BARNERS et al., 2002).

A água não sofre nenhum fracionamento nas frações de 160 e 180 durante a absorção pelas plantas, porém quando a água atinge as partes mais expostas da planta, como folhas e frutos, que sofrem intensa evaporação, ocorre um enriquecimento do isótopo 180 na água residual das células. A água presente nas partes comestíveis das plantas e que serão utilizadas como matéria-prima refletirá a razão 180/160 da planta de origem, que consequentemente será diferente da razão isotópica da água do ambiente. A origem da água utilizada pela planta influencia a razão isotópica de oxigênio conforme a região e clima (BRÉAS et al, 1994).

O delineamento experimental utilizado foi inteiramente casualizado. Foi considerado cada tempo de extração como um tratamento. As análises de determinação da razão isotópica foram realizadas com dez repetições, calculando-se a média entre todos os resultados obtidos para cada tratamento.

As médias obtidas foram analisadas através do programa Statgraphics V.7.1 (Bitstream, Cambridge, MN). Quando a análise de variância (ANOVA) indicou valores significativos de F, as amostras foram comparadas entre si e o teste de Fischer (LSD) foi utilizado para determinar as diferenças entre os tratamentos.

\section{Análise dos resultados}

As médias obtidas das repetições realizadas para cada um dos doze tratamentos, com diferentes tempos de extração de suco de uva estão apresentadas na Tabela 2. 
Tabela 2- Médias da razão isotópica 180/16O (\%o) da água em suco de uva cv. Bordô

\begin{tabular}{ccc}
\hline Amostra & Tratamento (minutos) & Média $(\mathbf{1 8 0} / \mathbf{1 6 0}(\mathbf{\% o}))^{*}$ \\
\hline 1 & 15 & $-6,80 \pm 0,05 \mathrm{~b}$ \\
2 & 30 & $-7,00 \pm 0,04 \mathrm{a}$ \\
3 & 45 & $-6,00 \pm 0,03 \mathrm{~d}$ \\
4 & 60 & $-5,90 \pm 0,06 \mathrm{de}$ \\
5 & 75 & $-5,70 \pm 0,05 \mathrm{efg}$ \\
6 & 90 & $-5,80 \pm 0,05 \mathrm{def}$ \\
7 & 105 & $-5,70 \pm 0,05 \mathrm{efg}$ \\
8 & 120 & $-5,70 \pm 0,06 \mathrm{efg}$ \\
9 & 135 & $-5,50 \pm 0,05 \mathrm{~g}$ \\
10 & 150 & $-6,50 \pm 0,04 \mathrm{c}$ \\
11 & 165 & $-5,60 \pm 0,06 \mathrm{fg}$ \\
12 & 180 & $-6,50 \pm 0,05 \mathrm{c}$ \\
\hline
\end{tabular}

*Valores médios seguidos de letras distintas diferem entre si a $5 \%$ de probabilidade de erro. Fonte: Autor

A obtenção de valores negativos indica que as amostras contém menor quantidade do isótopo mais pesado e valores positivos indicariam que as amostras analisadas possuíam quantidades maiores do isótopo mais pesado que o modelo.

Observou-se diferença significativa entre os tratamentos que apresentaram os menores tempos de extração e entre os maiores tempos. Os tratamentos a partir de 45 até 135 minutos de extração apresentaram comportamento semelhante. Pode-se observar que esses tempos de extração representam o período intermediário do experimento, sendo um período em que se mantem quase inalterada a razão isotópica.

Pode-se observar, através da Figura 2, que as maiores médias de incorporação de água exógena foram encontrados no primeiro e segundo tratamentos e no décimo e décimo segundo tratamento.

Figura 2 - Médias da razão isotópica 180/16O (\%) da água do suco de uva

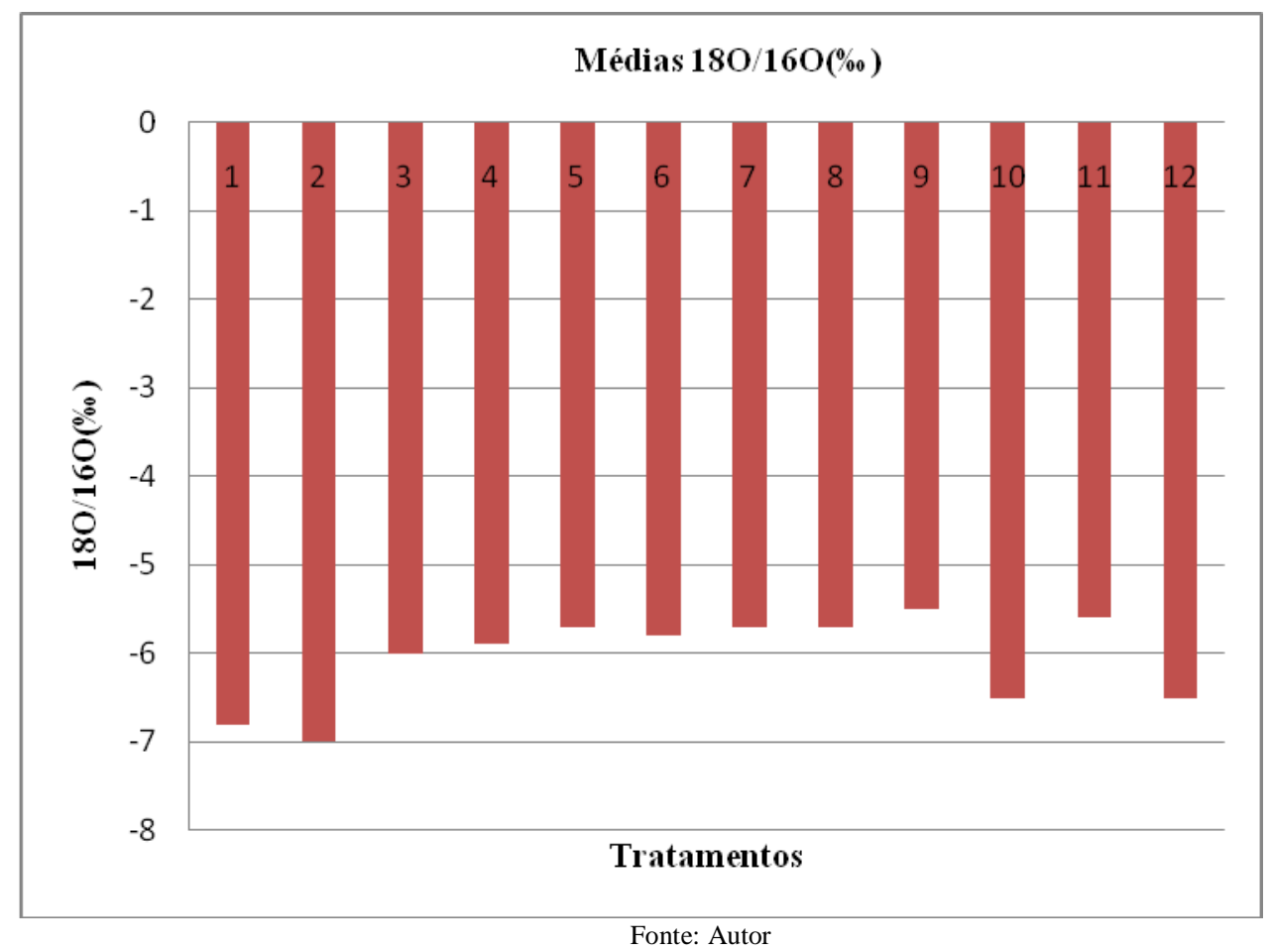


A maior incorporação de água no início do processo pode ser devido a condensação do vapor ao entrar em contato com a superfície fria do equipamento. Cristofoli (2007) também constatou maior diluição no suco de uva obtido pelo método de arraste a vapor no primeiro tempo de tratamento, com 20 minutos de extração.

O maior valor médio encontrado foi no tratamento 2.

Os maiores valores médios encontrados nos tratamentos com períodos de extração mais longos deve-se ao acúmulo de água gerado durante a extração. De acordo com Cristofoli (2007) o tamanho da panela extratora e o formato da tampa podem ter influência na quantidade de água incorporada, pois o vapor condensado na tampa retorna para o produto.

Na tabela 3 são descritos os valores de $\mathrm{pH}$ e ${ }^{\circ}$ Brix encontrados para cada tempo de extração.

Tabela 3- Valores de $\mathrm{pH} \mathrm{e}{ }^{\circ}$ Brix nas amostras de suco de uva cv. Bordô nos diferentes de extração

\begin{tabular}{ccc}
\hline Amostra & $\mathbf{p H}$ & ${ }^{\circ} \mathbf{B r i x}$ \\
\hline 1 & $2,90 \mathrm{a}$ & $7,5 \mathrm{~b}$ \\
2 & $2,86 \mathrm{a}$ & $7,5 \mathrm{~b}$ \\
3 & $2,86 \mathrm{a}$ & $7,75 \mathrm{ab}$ \\
4 & $2,87 \mathrm{a}$ & $7,75 \mathrm{ab}$ \\
5 & $2,88 \mathrm{a}$ & $7,75 \mathrm{ab}$ \\
6 & $2,88 \mathrm{a}$ & $8,00 \mathrm{a}$ \\
7 & $2,87 \mathrm{a}$ & $8,00 \mathrm{a}$ \\
8 & $2,88 \mathrm{a}$ & $8,00 \mathrm{a}$ \\
9 & $2,9 \mathrm{a}$ & $8,00 \mathrm{a}$ \\
10 & $2,9 \mathrm{a}$ & $8,00 \mathrm{a}$ \\
11 & $2,91 \mathrm{a}$ & $8,00 \mathrm{a}$ \\
12 & $2,93 \mathrm{a}$ & $8,00 \mathrm{a}$ \\
\hline *Valores médios seguidos de letras distintas diferem entre si a 5\% de probabilidade de erro.
\end{tabular}

Os valores de ${ }^{\circ}$ Brix encontrados são inferiores ao mínimo exigido pela Instrução Normativa $\mathrm{n}^{\circ} 01 / 2000$, do MAPA, que determina um valor mínimo para o Brix do suco de uva em $14^{\circ}$ Brix. O valor de ${ }^{\circ}$ Brix das amostras 1 e 2 diferiram das amostras 6 a 12, enquanto que as demais amostras não diferiram entre si.

$\mathrm{O}$ valor de $\mathrm{pH}$ não diferiu significativamente entre as amostras, mantendo-se entre 2,86 e 2,93 .

Manfroi et al. (2005) avaliaram a produção de suco de uva utilizando a panela extratora e uvas produzidas na região da Depressão Central do Rio Grande do Sul, como uma alternativa para as áreas não tradicionais de produção vitivinícola, utilizando tecnologia de baixo custo. As análises físico-químicas e sensoriais mostraram que as características do suco obtido obedecem os padrões de identidade e qualidade e foram bem aceitos pelos julgadores. No entanto, a existência de água exógena não foi avaliada neste trabalho.

Venturin (2004), em observações empíricas realizadas em agroindústrias dos municípios de Ipê e Antônio Prado, RS que produziam suco de uva, constatou que a temperatura de extração não é 
controlada, o que ocasiona, invariavelmente problemas no produto final. Em geral esses problemas estão relacionados ao sabor e aroma dos sucos. Quando a temperatura de extração atinge $90^{\circ} \mathrm{C}$ existe a probabilidade de ocorrer a condensação do vapor no interior do depósito, aumentando a quantidade de água exógena no suco (VENTURIN, 2004). A falta de controle nos processos dificulta a obtenção de produtos padronizados. De acordo com Tressler (1961) a alta temperatura e o tempo de extração longo, apesar de melhorar a extração dos compostos responsáveis pela cor, interfere de forma negativa na composição química do suco, independente do método utilizado.

De acordo com Rizzon et al. (1997), o aquecimento do suco de uva não poderia ultrapassar a temperatura de 85 a $90{ }^{\circ} \mathrm{C}$ por um período superior a 15 segundos, com o objetivo de evitar um princípio de caramelização dos açúcares e consequente gosto de cozido. Neste trabalho a temperatura de extração do suco não foi monitorada, no entanto considerando que as temperaturas para garantir a pasteurização com envase a quente devem ser superiores a $75{ }^{\circ} \mathrm{C}$ e os tempos de extração variaram de 15 minutos a 3 horas, pode-se esperar que temperaturas próximas aos 85 e 90 ${ }^{\circ} \mathrm{C}$ foram alcançadas e por períodos superiores aos 15 segundos recomendados.

Venturin (2004) observou, que o suco obtido sem controle de temperatura foi o que apresentou o maior volume de água exógena incorporado, enquanto o suco obtido por extração a 60 ${ }^{\circ} \mathrm{C}$ foi o que apresentou o menor volume adicionado, foi observado claramente o aumento do volume de água exógena incorporada ao suco conforme o aumento da temperatura. Observou-se também que houve uma redução do Brix do suco em comparação ao Brix do mosto devido a diluição dos açúcares pela água exógena incorporada. O menor tempo de extração, considerando o final da extração como o momento em que o fluxo de suco não era mais contínuo, foi observado para o tratamento sem controle da temperatura, fato devido a despolimerização da pectina, que ocorre em altas temperaturas e a maior adição de água exógena, fatores que facilitam o escoamento do suco (VENTURIN, 2004).

Rizzon e Link (2006) também observaram valores baixos de Brix nos sucos de uva obtidos pelo método de arraste a vapor devido ao efeito da diluição do vapor de água. No entanto, Pinheiro et al. (2009) concluiram em seu trabalho que o processo de extração a vapor do suco de uva da cultivar Benitaka apresentou bons resultados no que se refere as características físico-químicas, minerais e de estabilidade do produto.

Pode ser visto que no método de arraste a vapor a maior incorporação de água exógena ocorre nos primeiros 30 minutos, devido a condensação do vapor ao entrar em contato com a superfície fria do equipamento e aos 150 e 180 minutos devido ao acúmulo de água gerado durante o processamento. 
O fato de não haver parâmetros definidos para o suco de uva dificulta a determinação da \% de água exógena incorporada, assim seria importante a criação de uma Instrução Normativa própria para a determinação da razão isotópica 180/160 e \% de água exógena incorporada em suco de uva.

\title{
4. Conclusões
}

Pode-se concluir que no processo de extração de suco de uva pelo método de arraste a vapor ocorre a incorporação de água exógena, proveniente do vapor utilizado. A quantidade de água exógena incorporada depende do tempo de extração. A maior incorporação de água ocorre nos primeiros 30 minutos e nos últimos 150 e 180 minutos de extração.

\section{Agradecimentos:} financeiro.

Ao Conselho Nacional de Desenvolvimento Científico e Tecnológico (CNPq), pelo auxílio

\begin{abstract}
Juice consumption has lately increased due to the higher demand for healthy foods, and grape juice is considered as beneficial to human health as it contains a great amount of antioxidant substances. In the period of January to March of the current year, grape juice sales were $22.31 \%$ higher than in the same period in 2010. The Steam Extraction Method used in grape juice is largely used by small farmers in the mountain area of Rio Grande do Sul state, who industrialize their production, adding value to the raw material and increasing their income. The equipment used for that activity has a low cost and is easy to handle. However, due to the contact of the raw material and the steam, this method adds exogenous water to the juice, which de-characterizes the denomination of pure grape juice, besides providing dilution to the content of soluble solids. This experiment aimed to check the exogenous water incorporated to the grape juice, through the determination of the isotope ratio of 180/160 of the water incorporated during the processing, at time intervals of 15 minutes, for a period of three hours. It was found that the largest water incorporation occurred during the first 30 minutes of extraction, and then starting at 150 minutes.
\end{abstract}

Key-words: grape juice; exogenous water; extracting pan.

\section{Referências}

BARNERS, J. D. Análise Química Quantitativa. Rio de Janeiro: LTC Editora., 2002.

BRASIL. Ministério da Agricultura, Pecuária e Abastecimento. Decreto n. 99066 , de 08 de março de 1990. Regulamenta a Lei n. ${ }^{\circ}$ 7.678, de 08 de novembro de 1988 , que dispõe sobre a produção, circulação e comercialização do vinho e derivados do vinho e da uva disponível em $<$ http://extranet.agricultura.gov.br/sislegis/action/detalhaAto.do?method=consultarLegislacaoFederal>. Acesso em 15 mai. 2011.

BRASIL. Ministério da Agricultura, Pecuária e Abastecimento. Decreto n. ${ }^{\circ} 6871$, de 04 de junho de 2009. Regulamenta a Lei n. ${ }^{\circ} 8.918$, de 14 de julho de 1994, que dispõe sobre a padronização, a classificação, o registro, a inspeção, a produção e a fiscalização de bebidas, disponível em < http://extranet.agricultura.gov.br/sislegis/action/detalhaAto.do?method=consultarLegislacaoFederal>. Acesso em 29 jun. 2011. 
BRASIL. Ministério da Agricultura, Pecuária e Abastecimento. Instrução Normativa n. ${ }^{\circ} 10$, de 14 de abril de 2010. Oficializa a metodologia analítica para determinação da razão isotópica180/160 da água dos vinhos, disponível em <http://extranet.agricultura.gov.br/sislegis/action/detalhaAto.do?method=consultarLegislacaoFederal>. Acesso em 06 mai. 2011.

BRASIL. Ministério da Agricultura, Pecuária e Abastecimento. Instrução Normativa n. ${ }^{\circ} 01$, de 07 de janeiro de 2000. Aprova o Regulamento Técnico Geral para fixação dos Padrões de Identidade e Qualidade para polpa de fruta e aprova os Regulamentos Técnicos para Fixação dos Padrões de Qualidade e Identidade para polpa das seguintes frutas: acerola, cacau, cupuaçu, graviola, açaí, maracujá, caju, manga, goiaba, pitanga, uva, mamão, cajá, melão, mangaba, e para suco das seguintes frutas: maracujá, caju, caju alto teor de polpa, caju clarificado ou cajuína, abacaxi, uva, pêra, maçã, limão, lima ácida laranja, e disponível em $<$ http://extranet.agricultura.gov.br/sislegis/action/detalhaAto.do?method=consultarLegislacaoFederal>. Acesso em 13 mai. 2011.

BRASIL. Ministério da Agricultura, Pecuária e Abastecimento. Instrução Normativa n. ${ }^{\circ} 12$, de 04 de setembro de 2003. Aprova o Regulamento Técnico para fixação dos padrões de identidade e qualidade gerais para suco tropical, disponível em: < http://extranet.agricultura.gov.br/sislegis/action/detalhaAto.do?method=consultarLegislacaoFederal>. Acesso em 19 jun. 2011.

BRASIL. Ministério da Agricultura, Pecuária e Abastecimento. Lei n. ${ }^{\circ}$ 7678, de 08 de novembro de 1988 . Dispõe sobre a produção, circulação e comercialização do vinho e derivados da uva e do vinho, e dá outras providências, disponível em <http://extranet.agricultura.gov.br/sislegis/action/detalhaAto.do?method=consultarLegislacaoFederal>. Acesso em 15 mai. 2011.

BRÉAS, A. R. et al. Isotope ratio mass spectrometry: analysis of wines from different European countries. Rapid Communications in Mass Spectrometry. n. 8, p. 967-970, 1994. http://dx.doi.org/10.1002/rcm.1290081212

CAINELLI, J. C. Suco de Uva-Bebida Saudável. Bento Gonçalves, disponível em <http://www.enologia.org.br/conteudo.asp?id_artigo=353\&id_categoria=5\&sTipo=artigo\&sSecao=artigos\&sSubSecao =\&bSubMenu=1\&sParamMenu>. Acesso em 06 mai. 2011.

CAMARGO, U. A. Suco de uva: matéria-prima para produtos de qualidade e competitividade. In: Congresso Latino Americano de Viticultura e Enologia. Anais...Bento Gonçalves: Embrapa Uva e Vinho, 2005.

CRISTOFOLI, B. Influência do tempo de extração na composição e na razão isotópica 180/160 da água do suco de uva elaborado pelo método de arraste a vapor. Bento Gomçalves, 2007. 39f. Trabalho de Conclusão de Curso (Graduação)-Tecnologia em Viticultura e Enologia, Centro Federal de Educação Tecnológica de Bento Gonçalves.

DANI, C.; OLIBONI, L. S.; HENRIQUES, J. A. P.; SALVADOR, M. Suco de Uva: componentes e benefícios para a saúde. Bento Gonçalves, 2011, disponível em <http://www.grapejuiceofbrazil.com/secao.php?pagina=7>. Acesso em 06 mai. 2011.

IBRAVIN. Instituto Brasileiro do Vinho. A Vitivinicultura Brasileira, disponível em < http://www.ibravin.org.br/brasilvitivinicola.php>. Acesso em 15 mai. 2011.

IPÊ. Centro de Agricultura Ecológica. Agroindústria Artesanal: uma opção para a agricultura familiar. Ipê: CAE Ipê, 1997.

MANFROI, V.; MASCHIO A.; LUZ, F.F. Elaboração de sucos de uva na Depressão Central do Rio Grande do Sul: uma alternativa viável. . In: Congresso Latino Americano de Viticultura e Enologia, 10. Anais...Bento Gonçalves: Embrapa Uva e Vinho, 2005.

MARZAROtTO, V. Suco de Uva. In: VENTURINI FILHO, W. G. Bebidas Não Alcoólicas. São Paulo: Edgard Blucher, 2010. p. 359-385.

PINHEIRO, E. S.; COSTA, J. M. C.; CLEMENTE, E.; MACHADO, P. H. S.; MAIA, G. A. Estabilidade físico-química e mineral do suco de uva obtido por extração a vapor. Revista Ciências Agronômicas, v. 40, n. 3, p. 373-380, 2009.

RIZZON, L. A.; LINK, M. Composição do suco de uva caseiro de diferentes cultivares. Revista Ciência Rural, v. 36, n.2, p. 689-692, 2006.

RIZZON, L. A.; MENEGUZZO J. Suco de Uva. Brasília-DF: Embrapa Informação Tecnológica, 2007. 
RIZZON, L.A.; MANFROI, V.; MENEGUZZO, J. Elaboração de suco na propriedade vitícola. Bento Gonçalves: Embrapa Uva e Vinho, 1997. http://dx.doi.org/10.1590/S0103-84782006000200055

TRESSLER, D. K. Fruit and vegetable juice: processing technology. Westport: Avi, 1961.

USBERCO, J.; SALVADOR, E. Química. São Paulo: Saraiva., 1999.

UVIBRA. União Brasileira de Vitivinicultura. Comercialização de Vinhos e Derivados Elaborados de 2006 a 2011 , disponível em:<http://www.uvibra.com.br/pdf/comercializacao2006a2011_mar.pdf>. Acesso em 15 mai. 2011.

VENTURIN, L. Influência da temperatura de extração na elaboração de suco de uva Isabel (vitis labrusca) pelo método de arraste a vapor. Bento Gonçalves, 2004. 31f. Trabalho de Conclusão de Curso (Graduação)-Tecnologia em Viticultura e Enologia, Centro Federal de Educação Tecnológica de Bento Gonçalves.

VOGT, E. La Fabricacion de vinos. Zaragoza: Editorial Acribia, 1973.

Submetido em 05 dez 2011, Aceito para publicação em 21 dez. 2012. 